\title{
Impact of Parental Personality on Crying Child Behavior and Their Future Mental Health
}

\author{
Rupali Chandola ${ }^{1} *$, S. C. Tiwari ${ }^{2}$, Rakesh Kumar Tripathi ${ }^{3}$
}

\section{ABSTRACT}

Background: Crying is an important means of communication for babies. It plays a crucial role in ensuring the survival, health and development of the child. Whether infants cry intensely for a few months or fuss frequently for the first year of life, a systems approach to development would suggest that the impact of extremes in crying on the infant's immediate environment may have negative consequences for the dynamics of the parent-child relationship, which in turn would have implications for the child's psychosocial development. Parents have important roles in child rearing, but the influence of their personality on rearing practices and their impact on the behavior of children has received surprisingly little attention. The aim of the current study was to investigate the relationship between parent's personality and child crying behavior and future mental health. Methods: Study examined personality dimension of 300 parents of normal and psychiatrically ill male and female subjects selected purposively between 20-25 years age group. A question was asked to all the parents of the subjects, "What was the behavior of the subject during two years from the birth? Was he or she used to 'cry' often or not? The study was conducted on the parents of diagnosed 75 indoor and outdoor psychiatric patients and 75 normal controls. GHQ-12 negative subjects from the community formed the normal group. Dimension Personality Inventory (DPI) was administered on all parents of included subjects. Result: Significant difference was found in all the dimensions of DPI between 'crying' and 'non crying' child's parents. Conclusion: The maturity of parent's character appears to have a key role in reducing the risk of behavior problems in their children. Suggestions are made for parental education and future research.

Keywords: Crying behavior, Personality, psychiatric disorder, parents-child relationship, DPI

\footnotetext{
${ }^{1}$ Department of Psychology, Kumaun University Campus, Almora, Uttrakhand, India

${ }^{2}$ Professor and Head, Department of Geriatric Mental Health, King George’s Medical University, U.P. Lucknow, India

${ }^{3}$ Assistant Professor cum Clinical Psychologist, , Department of Geriatric Mental Health, King George's Medical University, U.P. Lucknow, India

*Responding Author

(C) 2016, R Chandola, S Tiwari, R Tripathi; licensee IJIP. This is an Open Access Research distributed under the terms of the Creative Commons Attribution License (http://creativecommons.org/licenses/by/2.0), which permits unrestricted use, distribution, and reproduction in any Medium, provided the original work is properly cited.
} 
Impact of Parental Personality on Crying Child Behavior and Their Future Mental Health

It has been mentioned by several researchers (Wolff PH, 1987; Brazelton TB, 1962: Barr RG.1990; Barr RG, et.al.2000) that the development of an offspring's personality is considerably influenced by the parents, through there facial relationship. The personality of the parents determine their influence on the child to a great extent (Lester BM, et.al.1990;Wessel MA et.al.1954;Gormally,S.et.al.1997).There are various factors influencing later behavioral problems, ranging from a genetic predisposition to parenting style to stress experienced while still in the womb, parents personality. Exactly how these factors interact and play out during a child's development is not well understood, but researchers have noted that childhood environment, including parenting style, in combination with infant fussiness are powerful predictors of future problems. Each stage of human development is characterized by a unique set of behaviors and emotional challenges: the terrible twos and temper tantrums, adolescence and rebellion, middle age and discontentment, the later years and loneliness. When these "normal" stages of development are coupled with individual temperamental differences and the occasional but inevitable environmental stressors, a range of dysfunctional responses - transient or chronic, inconsequential or debilitating - may result. This is baseline for everyone.

There has been extensive research examining the relationship of family environment and parenting on the adjustment of children (Baumrind, 1967; Bowlby, 1969). In particular, it has been well documented that parental abuse and neglect have a negative impact on the adaptation of children (Patterson, DeBaryshe \& Ramsey, 1989). In addition, psychopathology in parents, such as depression in mothers (Downey \& Coyne, 1990; Goodman \& Gotlib, 1999) or emotional distress of parents (Anthony et al., 2005; Õstberg, 1998) are predictive of their children's problem behaviors. The relations between the temperaments of parents and their children have also been shown to influence the risk of children's problem behaviors (Lee, 2012; Rettew et al., 2006).

However, few studies have directly studied the role of the maturity and integration of parents' personality on the risk of their children's behavior problems: the studies provided above have not included the parent's character dimensions with temperament dimensions (Josefsson et al., 2013a). An individual's personality involves more than their temperament; it includes the way a person regulates his or her goals and values to achieve a long-term purpose, such as rearing healthy children. Some studies have described the relationship between parents' personality and specific child problem behaviors, such as antisocial behaviors and depression (Bates et al., 1991; Brenning et al., 2011; Davies et al., 2012; Nigg \& Hinshaw,1998). That is, most of the past studies have measured abnormal traits in parents, and have not distinguished temperament and character of parents. Therefore, more research is needed about the role of healthy character traits in parents and its impact on children's behavior problems.

The aim of the current study was to investigate the impact of parental personality on child crying behavior and their future mental health. Furthermore, we sought to distinguish the roles of

(c) The International Journal of Indian Psychology, ISSN 2348-5396 (e) | ISSN: 2349-3429 (p) | 101 
temperament and character in parents on the risk of behavior problems in their children in order to identify those aspects of personality that have the greatest impact on effective child rearing.

\section{METHODS}

\section{Participants:}

Study examined personality dimension of 300 parents of normal (150) and diagnosed psychiatrically ill male and female subjects (150) selected purposively between 20-25 years age group from Pt. Deendayal upadhyay joint hospital, district Moradabad, U.P, India. \& Noormanzil Psychiatric Clinic \& Hospital, Lucknow, U.P. India. GHQ-12 negative subjects (score $<3$ ) from the community formed the normal group. Mean age of the parents of normal group was found to be 48.24 year with standard deviation of 4.10 years and in the other group mean age was found to be 50.76 years with standard deviation of 4.79 years.

\section{Tools:}

General Health Questionnaire-12 (GHQ-12): The 12-Item General Health Questionnaire (Jacob et al. 1997) is the most extensively used screening instrument for common mental disorders, in addition to being a more general measure of psychiatric well-being.

Dimension personality inventory (DPI): It is constructed by Bhargava (2012) and deals with six dimensions by which ones personality can be evaluated. They are: 'Activity- passivity', 'enthusiastic-non enthusiastic', 'assertive-submissive', 'suspicious-trusting', 'depressive-non depressive’ and ‘emotional instability-emotional stability’. It is similarly applicable for normal as well as psychotic patients. Score 10 or more indicative of left sided dominated personality on that dimension and score less than 10 indicative of the other side of that dimension. For example if person scored 15 on the dimension 'activity-passivity', he/she is active.

\section{Procedure:}

Parents of diagnosed cases of schizophrenia, bipolar and conversion disorder selected purposively from the indoor and outdoor ward of Pt. Deendayal upadhyay joint hospital, district Moradabad, U.P, India \& Noormanzil Psychiatric Clinic \& Hospital, Lucknow, U.P. India. and GHQ12 negative subject's parents were included in the study. A question was specifically asked to all the parents of the subjects, "What was the behavior of the subject during two years from the birth? Was he or she used to 'cry' often (irritating and excessive crying) or not? Dimension Personality Inventory (DPI) was administered on all parents of included subjects.

Keeping view the main objectives of the present study chi-square with Yates's correction wherever applicable was employed to see the difference between crying and none crying behavior child and future mental health. 


\section{RESULTS}

The result of the present study has been given below and consecutively discussed.

\section{Table-1 Personality of parents of crying and non crying behaviour children}

\begin{tabular}{|llccccc|}
\hline & DPI -B Dimensions & Group & $\mathbf{N}$ & Mean & S.D. & t- value \\
\hline \multirow{2}{*}{1} & Activity- Passivity & Crying child's parents & 150 & 9.53 & 3.93 & $13.28 * \mathrm{df}=298$ \\
& & Non crying child's parents & 150 & 14.95 & 3.10 & $\mathrm{P}<0.01$ \\
2 & Enthusiastic-Non & Crying child's parents & 150 & 9.37 & 3.84 & $14.51^{*} \mathrm{df}=298$ \\
& enthusiastic & Non crying child's parents & 150 & 15.28 & 3.18 & $\mathrm{P}<0.01$ \\
3 & Assertive- Submissive & Crying child's parents & 150 & 10.9 & 3.79 & $10.70^{*} \mathrm{df}=298$ \\
& & Non crying child's parents & 150 & 15.12 & 2.99 & $\mathrm{P}<0.01$ \\
4 & \multirow{2}{*}{ Suspicious- Trusting } & Crying child's parents & 150 & 16 & 3.02 & $17.61^{*} \mathrm{df}=298$ \\
& & Non crying child's parents & 150 & 9.02 & 3.80 & $\mathrm{P}<0.01$ \\
5 & Depressive-Non depressive & Crying child's parents & 150 & 15.22 & 3.32 & $11.58 * \mathrm{df}=298$ \\
& & Non crying child's parents & 150 & 9.93 & 4.51 & $\mathrm{P}<0.01$ \\
6 & Emotional-instability- & Crying child's parents & 150 & 15.34 & 3.10 & $5.65^{*} \mathrm{df}=298$ \\
& Emotional stability & Non crying child's parents & 150 & 10.39 & 10.27 & $\mathrm{P}<0.01$ \\
\hline
\end{tabular}

*Significant at $\mathrm{p}<0.01$ level

Table 1 shows that there was significant difference in the mean scores $(\mathrm{p}<0.01)$ on all the dimensions of DPI between crying and non crying child's parents. In the dimension of 'ActivityPassivity', 'Enthusiastic- Non enthusiastic' the mean score of crying child's parents was found to be less than 10. It indicates that crying child's parents were more passive and non- enthusiastic in comparison to other group. But in the dimension 'Suspicious- Trusting' and 'Depressive-non depressive' the mean score of non crying child's parents was found to be less than 10. It indicates that non crying child's parents were more trusting and non depressive in comparison to crying child's parents.

\section{Table-2 Personality of crying child and non crying behaviour child father}

\begin{tabular}{|llccccc|}
\hline & DPI -B Dimensions & Group & N & Mean & S.D. & t- value \\
\hline \multirow{2}{*}{1} & Activity- Passivity & Crying child's father & 75 & 8.61 & 3.85 & $11.48 * \mathrm{df}=148$ \\
& & Non crying child's father & 75 & 15.10 & 3.02 & $\mathrm{p}<0.01$ \\
2 & Enthusiastic-Non- & Crying child's father & 75 & 9.10 & 3.40 & $12.39 * \mathrm{df}=148$ \\
& enthusiastic & Non crying child's father & 75 & 15.61 & 3.02 & $\mathrm{p}<0.01$ \\
3 & Assertive- Submissive & Crying child's father & 75 & 11.44 & 3.36 & $7.26 * \mathrm{df}=148$ \\
& & Non crying child's father & 75 & 15.24 & 3.04 & $\mathrm{p}<0.01$ \\
\multirow{2}{*}{4} & Suspicious- Trusting & Crying child's father & 75 & 15.29 & 3.07 & $10.55 * \mathrm{df}=148$ \\
& & Non crying child's father & 75 & 8.85 & 4.30 & $\mathrm{p}<0.01$ \\
5 & Depressive-Non depressive & Crying child's father & 75 & 14.56 & 3.29 & $10.49 * \mathrm{df}=148$ \\
& & Non crying child's father & 75 & 7.94 & 4.36 & $\mathrm{p}<0.01$ \\
6 & Emotional-instability- & Crying child's father & 75 & 15.04 & 2.92 & $8.93 * \mathrm{df}=148$ \\
& Emotional stability & Non crying child's father & 75 & 9.52 & 4.48 & $\mathrm{p}<0.01$ \\
\hline
\end{tabular}

*Significant at $\mathrm{p}<0.01$ level

Table 2 shows that there was significant difference in the mean scores $(p<0.01)$ on all the dimensions of DPI between crying and non crying child's father. In the dimension of 'Activity-

(c) The International Journal of Indian Psychology, ISSN 2348-5396 (e)| ISSN: 2349-3429 (p) | 103 
Passivity', 'Enthusiastic- Non enthusiastic' the mean score of crying child father was found to be less than 10. It indicates that crying child's father were more passive and non- enthusiastic in comparison to other group. But in the dimension 'Suspicious- Trusting' and 'Depressive-non depressive' and 'Emotional instability- Emotional stability' the mean score of non crying child's father was found to be less than 10. It indicates that non crying child's father were more trusting and non depressive and emotionally stable in comparison to crying child's father.

Table-3Personality of crying child and non crying behaviour child mother

\begin{tabular}{|llccccc|}
\hline & DPI -B Dimensions & Group & N & Mean & S.D. & t- value \\
\hline 1 & Activity- Passivity & Crying child's mother & 75 & 10.38 & 3.71 & $7.82^{*} \mathrm{df}=148$ \\
& & Non crying child's mother & 75 & 14.82 & 3.22 & $\mathrm{p}<0.01$ \\
2 & Enthusiastic-Non & Crying child's mother & 75 & 9.73 & 4.09 & $8.89 * \mathrm{df}=148$ \\
& enthusiastic & Non crying child's mother & 75 & 15.18 & 3.38 & $\mathrm{p}<0.01$ \\
3 & Assertive- Submissive & Crying child's mother & 75 & 10.52 & 4.34 & $7.38^{*} \mathrm{df}=148$ \\
& & Non crying child's mother & 75 & 15 & 2.96 & $\mathrm{p}<0.01$ \\
4 & Suspicious- Trusting & Crying child's mother & 75 & 17.13 & 2.70 & $16.44^{*} \mathrm{df}=148$ \\
& & Non crying child's mother & 75 & 9.21 & 3.18 & $\mathrm{p}<0.01$ \\
5 & Depressive-Non & Crying child's mother & 75 & 15.84 & 3.28 & $8.83^{*} \mathrm{df}=148$ \\
& depressive & Non crying child's mother & 75 & 10.33 & 4.29 & $\mathrm{p}<0.01$ \\
6 & Emotional instability- & Crying child's mother & 75 & 15.61 & 3.24 & $10.18^{*} \mathrm{df}=148$ \\
& Emotional stability & Non crying child's mother & 75 & 9.54 & 4.02 & $\mathrm{p}<0.01$ \\
\hline
\end{tabular}

*Significant at $\mathrm{p}<0.01$ level

Table 3 shows that there was significant difference in the mean scores $(p<0.01)$ on all the dimensions of DPI between crying and non crying child's mother. In the dimension of 'Enthusiastic- Non enthusiastic' the mean score of crying child mother was found to be less than 10. It indicates that crying child's mother were more non- enthusiastic in comparison to other group. But in the dimension 'Suspicious- Trusting' and 'Emotional instability- Emotional stability' the mean score of non crying child's mother was found to be less than 10 . It indicates that non crying child's mother were more trusting and emotionally stable in comparison to crying child's mother.

Table 4: Comparison of Health Status of Crying and non crying behavior child at adulthood:

\begin{tabular}{|cccc|}
\hline Characteristic of child & Normal & Psychiatrically Ill & $\mathrm{X}^{2}$ \\
\hline Crying Behaviour & $26(17.3 \%)$ & $60(40.0 \%)$ & $31.46^{*}$ \\
Non crying Behaviour & $49(32.6 \%)$ & $15(10.0 \%)$ & $\mathrm{p}<0.001$ \\
Total & 75 & 75 & \\
\hline
\end{tabular}

*Significant at $\mathrm{p}<0.01$ level

Table 4 shows that significantly more crying behaviour child suffering from psychiatric illness (40.0\%) at their adult hood compared to non crying behaviour child (10.0\%).

(C) The International Journal of Indian Psychology, ISSN 2348-5396 (e)| ISSN: 2349-3429 (p) | 104 
Impact of Parental Personality on Crying Child Behavior and Their Future Mental Health

Table-5 age wise distribution of crying behavior and its effect on future mental health

\begin{tabular}{|ccccccccc|}
\hline Category & Sex & $\begin{array}{c}\text { Duration } \\
\text { of crying } \\
\text { in } \\
\text { month }\end{array}$ & $\begin{array}{c}\text { Normal } \\
\text { N=75 }\end{array}$ & $\begin{array}{c}\text { Psychiatric morbidity= 75 } \\
\text { Bipolar } \\
\text { mood dis. }\end{array}$ & $\begin{array}{c}\text { Schizophrenia } \\
\text { Conversion } \\
\text { dis. }\end{array}$ & Total & X2 \\
\hline Crying & Male & $0-12$ & $3(6.81 \%)$ & $6(13.63 \%)$ & $5(11.36 \%)$ & $3(6.81 \%)$ & $14(18.66 \%)$ & 0.005 \\
behavior & $\mathrm{N}=44$ & $12-24$ & $5(11.36 \%)$ & $7(15 \%)$ & $12(27.27 \%)$ & $2(4.54 \%)$ & $22(29.33 \%)$ & N.S \\
N=75 & Female & $0-12$ & $12(28.57 \%)$ & $4(9.52 \%)$ & $1(2.38 \%)$ & $3(7.14 \%)$ & $8(10.66 \%)$ & $4.58^{*}$ \\
& $\mathrm{~N}=42$ & $12-24$ & $6(14.28 \%)$ & $3(7.14 \%)$ & $5(11.90 \%)$ & $8(19.04 \%)$ & $16(21.33 \%)$ & $\mathrm{P}<.05$ \\
Non & Male & $0-12$ & $16(44.44 \%)$ & $2(5.55 \%)$ & $0(0 \%)$ & $1(2.77 \%)$ & $3(4 \%)$ & 0.25 \\
crying & $\mathrm{N}=36$ & $12-24$ & $11(30.55 \%)$ & $1(2.77 \%)$ & $3(8.33 \%)$ & $2(5.55 \%)$ & $6(8 \%)$ & N.S \\
Behavior & Female & $0-12$ & $8(28.57 \%)$ & $1(3.57 \%)$ & $1(3.57 \%)$ & $2(7.14 \%)$ & $4(5.33 \%)$ & $4.18^{*}$ \\
N=75 & $\mathrm{N}=28$ & $12-24$ & $14(50 \%)$ & $0(0 \%)$ & $2(7.14 \%)$ & $0(0 \%)$ & $2(2.66 \%)$ & $\mathrm{P}<.05$ \\
\hline
\end{tabular}

*Significant at $\mathrm{p}<0.05$ level

Table 5 shows gender, year of crying 0-12 month and 12- 24 month wise distribution of crying and non crying behavior with their mental health status. Statistically significant difference $(p<0.05)$ was found in mental health status between 0-12 month and 12-24 month of age amongst female whose excessive crying during their childhood period. It was significantly high (21.33\%) and the other hand (28.57\%) belonging from non crying behavior activity in excessive range in their 0-12 month of age were found mentally fit or normal in future mental condition only (2.66\%) female found to be psychiatrically ill. This difference is also significant at $(\mathrm{p}<0.05)$

\section{DISCUSSION}

The current study investigated the association between parental personality and children's crying and non-crying behaviour up to 2 years of age. We found that participants belonging from excessive crying behavior during childhood having highly psychiatric morbidity (40\%) at their adult hood compared to non crying behaviour child $(10.0 \%)$. Significant difference $(\mathrm{p}<0.05)$ was found in mental health status between 0-12 month and 12-24 month of age amongst female whose excessive crying during their childhood period. Crying child's parents were more passive, dull, inactive, slow, irregular in working etc. and non- enthusiastic, reserved, shy, inhibited, difficult feeling to contact other people, slow spoken, none participating of various functions etc. in comparison to other group. Non crying child's father were more trusting and non depressive and emotionally stable in comparison to crying child's father. Non crying child's mothers were more trusting and emotionally stable in comparison to crying child's mother. Results also show that crying behavior children are more prone to develop psychiatric illness at their adulthood. Our study findings reveal that we try to improve or modify our personality in such a positive manner which impact positive mental health of our child. These positive personality characteristics are 'enthusiasm', 'assertiveness', 'trusting' and 'emotionally stable'. 
Impact of Parental Personality on Crying Child Behavior and Their Future Mental Health

\section{Limitation:}

Recall bias may be present as parents were asked to their child's crying and non-crying behaviour. Detailed mental health of the parents was not assessed.

\section{Acknowledgement:}

Authors are grateful to the Director and staff of Pt. Deendayal upadhyay joint hospital, district Moradabad, U.P, India for permission of data collection and study subjects \& for their cooperativeness.

\section{Conflict of Interest: None}

\section{REFERENCES}

Anthony LG, Anthony BJ, Glanville DN, Naiman DQ, Waanders C, Shaffer S. (2005).The relationships between parenting stress, parenting behaviour and preschoolers' social competence and behaviour problems in the classroom. Infant and Child Development.14:133-154.

Barr RG, Hopkins B, Green JA.(2000).Crying as a sign, symptom, and a signal: Clinical emotional and developmental aspects of infant and toddler crying. New York, NY: Cambridge University Press.

Barr RG. (1990). The normal crying curve: what do we really know? Developmental Medicine and Child Neurology; 32(4):356-362.

Bates JE, Bayles K, Bennett DS, Ridge B, Brown MM.(1991).Origins of externalizing behavior problems at eight years of age. In: Pepler D, Rubin K, editors. Development and treatment of childhood aggression. Hillsdale: Erlbaum; pp. 93-120.

Baumrind (1967) Baumrind D.Child care practices anteceding three patterns of preschool behavior. Genetic Psychology Monographs; 75:43-88.

Bhargawa, M. (2012).Dimensional Personality Inventory, National psychological corporation, Agra.

Bowlby (1969) Bowlby J. Attachment and loss, volume i: attachment. New York: Basic Books.

Brazelton TB.(1963).Crying in infancy. Pediatrics 1962;29(4):579-588.

Brenning K, Soenens B, Braet C, Bosmans G.(2011). The role of depressogenic personality and attachment in the intergenerational similarity of depressive symptoms: a study with early adolescents and their mothers. Personality \& Social Psychology Bulletin. 37:284-297.

Davies PT, Sturge-Apple ML, Cicchetti D, Manning LG, VonholdSE.(2012). Pathways and processes of risk in associations among maternal antisocial personality symptoms, inter parental aggression, and preschooler's psychopathology. Development and Psychopathology;24:807-832.

Downey, G, Coyne,JC. (1990). Children of depressed parents: an integrative review. Psychological Bulletin; 108:50-76. 
Impact of Parental Personality on Crying Child Behavior and Their Future Mental Health

Goodman SH, Gotlib IH.(1999). Risk for psychopathology in the children of depressed mothers: a developmental model for understanding mechanisms of transmission. Psychological Review;106:458-490.

Gormally S, Barr RG.(1997).Clinical pies and clinical cues: Proposal for a clinical approach to complaints of early crying and colic. Ambulatory Child Health;3(2):137-153.

Jacob, K.S., Bhugra, D., Mann, A.H. (1997).The validation of the 12-item General Health Questionnaire among ethnic Indian women living in the United Kingdom. Psychological Medicine, 27(5): 1215-17.

Josefsson et al. (2013a) Josefsson K, Jokela M, Cloninger CR, Hintsanen M, Salo J, Hintsa T, Pulkki-Raback L, Keltikangas-Jarvinen L. Maturity and change in personality: developmental trends of temperament and character in adulthood. Development and Psychopathology;25:713-727

Lee JY.(2012).Testing the relationship between child and mother's temperament and child's behavioral problems. Korean Journal of Clinical Psychology;31:801-822.

Lester BM, Boukydis CZ, Garcia-Coll CT, Hole WT.(1990).Colic for the develop mentalists. Infant Mental Health Journal;11(4):321-333

Nigg JT, Hinshaw SP. (1998).Parent personality traits and psychopathology associated with antisocial behaviors in childhood attention-deficit hyperactivity disorder. Journal of Child Psychology and Psychiatry and Allied Disciplines; 39:145-159.

Õstberg (1998) Õstberg M. Parental stress, psychosocial problems and responsiveness in helpseeking parents with small (2-45 months old) children. Acta Paediatrica; 87:69-76

Patterson, DeBaryshe \& Ramsey (1989) Patterson GR, DeBaryshe BD, Ramsey E.A developmental perspective on antisocial behavior. American Psychologist; 44:329-335.

Rettew DC, Stanger C, McKee L, Doyle A, Hudziak JJ.(2006).Interactions between child and parent temperament and child behavior problems. Comprehensive Psychiatry; 47:412-420.

Wessel MA, Cobb JC, Jackson EB, Harris GS, Detwiler AC. (1954).Paroxysmal fussing in infancy, sometimes called "colic". Pediatrics; 14(5):421-435

Wolff PH. (1987) The development of behavioral states and the expression of emotions in early infancy: New proposals for investigation. Chicago, Ill: University of Chicago Press.

How to cite this article: R Chandola, S Tiwari, R Tripathi (2016), Impact of Parental Personality on Crying Child Behavior and Their Future Mental Health, International Journal of Indian Psychology, Volume 3, Issue 4, No. 64, ISSN 2348-5396 (e), ISSN: 2349-3429 (p), DIP: 18.01.125/20160304, ISBN: 978-1-365-32519-9

(C) The International Journal of Indian Psychology, ISSN 2348-5396 (e) | ISSN: 2349-3429 (p) | 107 